doi: $10.2306 /$ scienceasia1513-1874.2014.40.193

\title{
Antioxidant activity of flavonoids from leaves of Jatropha curcas
}

\author{
Qiulan Huang, Yiran Guo, Rao Fu, Tong Peng, Yuting Zhang, Fang Chen* \\ Key Laboratory Bio-Resources and Eco-Environment, Ministry of Education, College of Life Science, \\ Sichuan University, 610064 Chengdu, China \\ ${ }^{*}$ Corresponding author, e-mail: Cfang@263.net \\ Received 25 Oct 2012 \\ Accepted 22 Jan 2014
}

\begin{abstract}
The objective of this study was to characterize the antioxidant properties of ethanol extracted from leaves of Jatropha curcas and to determinate the compounds. The $\mathrm{IC}_{50}$ values of DPPH (2,2-diphenyl-1-picrylhydrazyl) and ABTS (2,2'-azino-bis(3-ethylbenzothiazoline-6-sulphonic acid) diammonium salt) were found to be $7.47 \mathrm{and} 6.6 \mu \mathrm{g} / \mathrm{ml}$, respectively, for the extracts. The reducing power of the extracts increased from 0.09 to 0.16 , respectively, for $1-32 \mu \mathrm{g} / \mathrm{ml}$ of standard reagent. The assignment of the flavone compounds using HPLC-DAD-MS ${ }^{\mathrm{n}}$ was based on the evaluation of their UV-Vis absorption maxima $\left(\lambda_{\max }\right)$ and mass spectral analyses. Tentatively, 4 compounds (orientin, vitexin, isovitexin, rhoifolin) were identified.
\end{abstract}

KEYWORDS: oil plant, in vitro antioxidant, HPLC-MS

\section{INTRODUCTION}

Jatropha curcas belongs to the Euphorbiaceae family and is an ideal biodiesel crop in most arid areas of Asia, particularly in southeast Asia ${ }^{1,2}$, South America, and Africa, because of its high oil (43-61\%) seed kernel $^{3,4}$. Traditionally, Jatropha seeds and other plant parts have been used to produce oil, soap, and medicinal compounds ${ }^{4-6}$. J. curcas grows readily in poor and stony soil, resists drought and disease, and yields high quality biodiesel ${ }^{7}$. The plant is a perennial plant, native and is widespread throughout many tropical countries ${ }^{8}$.

All parts of $J$. curcas can be used in traditional medicine or as raw materials for pharmaceutical and cosmetic industries. It cures many diseases, such as arthritis, jaundice, dental complaints, tumours, allergies, burns, cut wound, leprosy scabies, and smallpox $^{6,9}$. J. curcas contains proteins, peptides, diterpenes and a variety phytochemicals exhibiting a broad spectrum of biological activities ${ }^{10}$. The extract of root and latex of $J$. curcas plant which contains phenolic, flavonoid, diterpene, and saponin compounds shows notable antioxidant, anticancer, and anti-inflammatory activities ${ }^{11,12}$. The oil pulp can therefore be used as a protein source, and the root be used to produce acridine. Currently, there are many studies that examine the structure and function of natural source phenolic and flavonoid compounds, as well as their antioxidant, anticancer roles in noncommunicable diseases ${ }^{13,14}$.
The research for antioxidants from natural sources aims to identify compounds that may help to prevent oxidative damage in the body and contribute to the prevention of noncommunicable diseases ${ }^{15,16}$. The by-products of $J$. curcas such as leaves have not been comprehensively studied, therefore limited information is available on the feasible application of the meal as a potential source of bioactive compounds ${ }^{9}$. Hence the objective of the present study was to characterize this plant flavone compounds and its antioxidant activity. The information gathered would indicate that the leaves can be a potential source of bioactive compounds.

\section{MATERIALS AND METHODS}

\section{Chemicals}

All the chemicals used in the study were of analytical or HPLC grade. Except for $\mathrm{AlCl}_{3}$, TCA, ascorbic acid (AA), ABTS (2,2'-azino-bis(3-ethylbenzothiazoline6-sulphonic acid) diammonium salt), potassium ferricyanide, apigenin, luteolin, DPPH (2,2-diphenyl1-picrylhydrazyl), apigenin-7-O-neohesperidoside, all other chemicals used were of analytical grade from Chengdu Kelon Chemical Reagent Company.

\section{Plant materials and extract preparation}

J. curcas leaves were collected from Sichuan, China, and were dried naturally and crushed. According to the method established by our tests, the compounds were quantified under the optimal conditions (data 
not shown). The ethanol extracts were concentrated until all the ethanol was removed. The solution was sequentially extracted by petroleum ether, ethyl acetate, and n-butyl alcohol. The ethyl acetate phase was the test sample and the other phases were kept to be analysed later.

\section{Radical DPPH scavenging activity}

The free radical activity with DPPH as a free radical was determined following a modified method ${ }^{17,18}$. Different concentrations $(1-32 \mu \mathrm{g} / \mathrm{ml})$ of the sample and AA, as positive control, were prepared. A $100 \mu \mathrm{l}$ aliquot of each sample/standard solution was mixed with $100 \mu \mathrm{l}$ of DPPH solution. The mixture was incubated at RT for $30 \mathrm{~min}$. The DPPH reacted with the tested extract and antioxidant to decrease the absorbance at $517 \mathrm{~nm}$. The scavenging capability to the DPPH radical was calculated as $\left(1-\left(A_{\mathrm{i}}-A_{\mathrm{j}}\right) / A_{\mathrm{c}}\right)$, where $A_{\mathrm{i}}$ is the initial absorbance of the DPPH radical, $A_{\mathrm{j}}$ is the absorbance of the sample, and $A_{\mathrm{c}}$ is the absorbance of the DPPH without sample.

\section{ABTS radical-scavenging activity}

Various concentrations $(1-32 \mu \mathrm{g} / \mathrm{ml})$ of samples and AA were prepared. ABTS was dissolved in distilled water to a final concentration of $7 \mathrm{mM}$ and mixed with a potassium persulphate solution at a final concentration of $2.45 \mathrm{mM}$. The mixture was left to settle at room temperature for $12-16 \mathrm{~h}$ in the dark before use. For each experiment, a freshly prepared ABTS solution was diluted with $0.2 \mathrm{M}$ phosphate buffer (PBS, $\mathrm{pH}$ 7.4) to adjust its absorbance to $100 \pm 100$ at $734 \mathrm{~nm}$ wavelength. Then, $100 \mu \mathrm{l}$ of each sample/standard solution was mixed with $100 \mu \mathrm{l}$ ABTS solution, and the absorbance were measured at $734 \mathrm{~nm}^{19}$. The scavenging capability of ABTS was calculated as before using $A_{\mathrm{i}}, A_{\mathrm{j}}$, and $A_{\mathrm{c}}$ for the initial absorbance of ABTS radical, absorbance of the samples, and absorbance of the ABTS without sample, respectively.

\section{Reducing power}

Reducing power activities of the extracts were determined following the method of $\mathrm{Hu}$ and $\mathrm{Xu}^{20}$ with some modifications: $0.1 \mathrm{ml}$ of each sample of the standard reagent (AA as positive control) at various concentrations $(1-32 \mu \mathrm{g} / \mathrm{ml})$ was mixed with $0.2 \mathrm{ml}$ of $\mathrm{Na}_{3} \mathrm{PO}_{4}$ buffer ( $\mathrm{pH}$ 6.6) and $0.1 \mathrm{ml}$ potassium ferricyanide $(100 \mathrm{mg} / \mathrm{ml})$ solution. Then the mixture was incubated at $50^{\circ} \mathrm{C}$ in a water bath for $1 \mathrm{~h}$ and mixed with $0.16 \mathrm{ml}$ of TCA $(100 \mathrm{mg} / \mathrm{ml})$ and $0.24 \mathrm{ml}$ of $\mathrm{FeCl}_{3}$ solution $(1 \mathrm{mg} / \mathrm{ml})$. The absorbance was measured at $700 \mathrm{~nm}$ wavelength ${ }^{21}$.

\section{The antioxidant activity of the main composition}

HPLC-DAD analysis was performed on the Shimadzu series HPLC systems equipped with a G13798 degasser, a G1312A binary pump, a G1329A autosampler, and a G1315D diode array detector. HPLC separation was achieved by using a C18 column $(250 \times 4.6 \mathrm{~mm}, 5 \mu \mathrm{m}$, Agilent Technologies $)$ at $25^{\circ} \mathrm{C}$. Elution was performed using a mobile phase A (water) and a mobile phase B (methanol), and the samples $(10 \mu \mathrm{l})$ were eluted at a flow rate of $0.8 \mathrm{ml} / \mathrm{min}$. The UV-Vis spectra were scanned from 190-700 nm on DAD with a detection wavelength of $268 \mathrm{~nm}$. The solvent gradient in volumetric rations varied from $40-70 \%$ B over 30 min.

\section{LC-DAD-MS (ESI-) analyses}

The mass spectra were obtained using an LTQ Orbitrap XL (Thermo, USA). The ESI conditions were as follows: methanolic extracts were used for the analysis of the HPLC-DAD conditions with a little modification. LC-ESI/MS/MS, a source voltage of $+3.0 \mathrm{kV}$, an auxiliary gas flow rate 10.01 , a vaporizer temperature of $43.5^{\circ} \mathrm{C}$, a capillary temperature $300^{\circ} \mathrm{C}$, a capillary voltage $-34.99 \mathrm{~V}$, and tube lens voltage $-110 \mathrm{~V}$.

\section{RESULT AND DISCUSSION}

\section{Antioxidant activity}

The 2,2-diphenyl-1-picrylhydrazyl is a stable free radical, and it has a single electron and strong absorption at $517 \mathrm{~nm}$. The synthetic nitrogen-centred DPPH free radical is not biologically relevant but widely used to determine antioxidant activity. In this study, the extracts and AA displayed radical scavenging activity (Fig. 1a). When mixed with an antioxidant, the antioxidant compound donates an electron to DPPH and the colour changes from purple to light yellow. The scavenging activity were ranged from $2 \%$ to $94 \%$ and $-1 \%$ to $96 \%$ for the extracted compounds and AA, respectively, with their concentrations from $1-32 \mu \mathrm{g} / \mathrm{ml}$. The concentrations at which $50 \%$ of the DPPH radicals were scavenged $\left(\mathrm{IC}_{50}\right)$, were 12.5 and $7.5 \mu \mathrm{g} / \mathrm{ml}$ for the extracts and AA, respectively.

ABTS is a well-known nitrogen-centred synthetic radical and is widely used to determine antioxidant activity. The ABTS radical is generated by oxidation of ABTS with potassium persulphate and when antioxidants are added to it, it is converted to a nonradical form. Different concentrations of extracts and AA, ranging from $1-32 \mu \mathrm{g} / \mathrm{ml}$, were examined for scavenging activity. The scavenging activity (Fig. 1b) ranged from $20 \%$ to $99.7 \%$ for the extract and from 

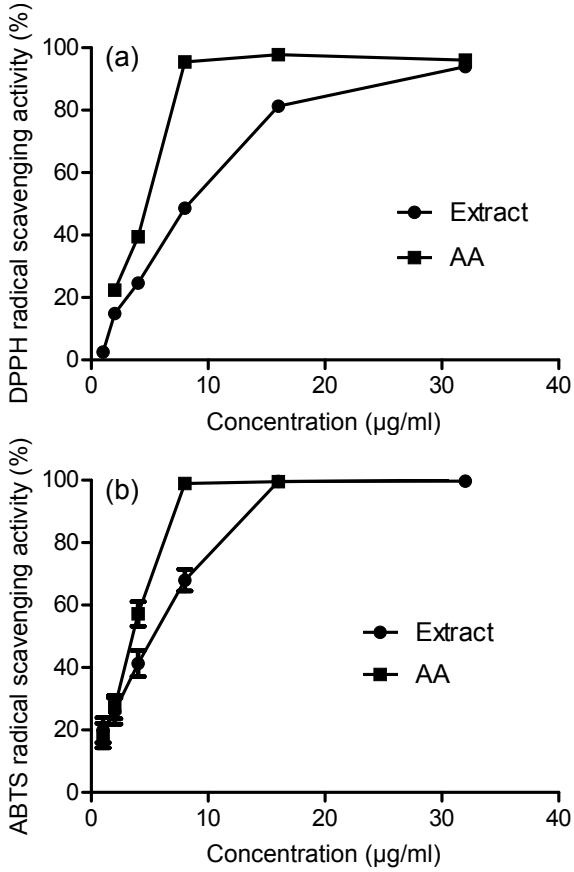

Fig. 1 Scavenging effects of J. curcas extract on (a) $\mathrm{DPPH}^{\text {* }}$ radicals, and (b) $\mathrm{ABTS}^{\circ}$ radicals.

$18 \%$ to $100 \%$ for $\mathrm{AA}$. In addition, the $\mathrm{IC}_{50}$ values were 6.6 and $4.1 \mu \mathrm{g} / \mathrm{ml}$ for extracts and AA, respectively. Besides, the antioxidant activity in the ABTS or DPPH assay were also strongly correlated with the contents of phenolic and flavonoid compounds ${ }^{21}$.

Reducing force is an important indicator to show the ability of the antioxidant to provide electronic ability. The antioxidants give out electrons through their own reduction give and make free radicals into stable molecules, and then lose activity. Antioxidants reduces iron potassium cyanide, that reduces its ferric iron into bivalent iron ion. The reducing power is larger, the stronger the antioxidant effect is. The $\mathrm{Fe}-\mathrm{Fe}$ reducing power of a compound is used to determine the electron donating capacity of antioxidants and is one of main characteristics of phenolic compounds ${ }^{22}$. The reducing power of the extract and AA increased from 0.09 to 0.16 and 0.11 to 1.00 , respectively, at $1-32 \mu \mathrm{g} / \mathrm{ml}$. The scavenging of the AA was significantly higher than that of the extract (Fig. 2).

The antioxidants clear the free radicals that are produced by the biological redox reactions. The radical DPPH scavenging activity, the ABTS radicalscavenging activity, and the reducing power in the experiment revealed that the flavone compounds from leaves of $J$. curcas had strong antioxidant activity, and the orientin played the main function (Fig. 3).

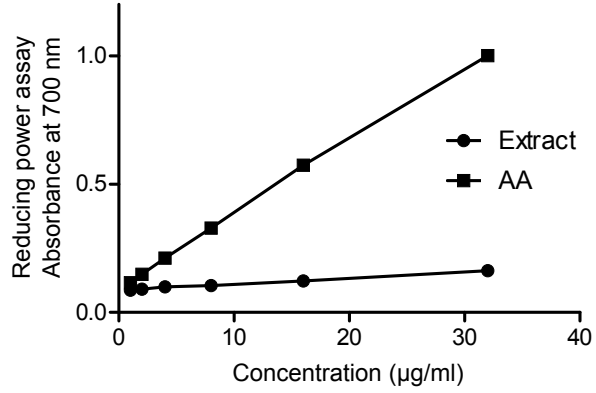

Fig. 2 Deoxidization capability of $J$. curcas extract.

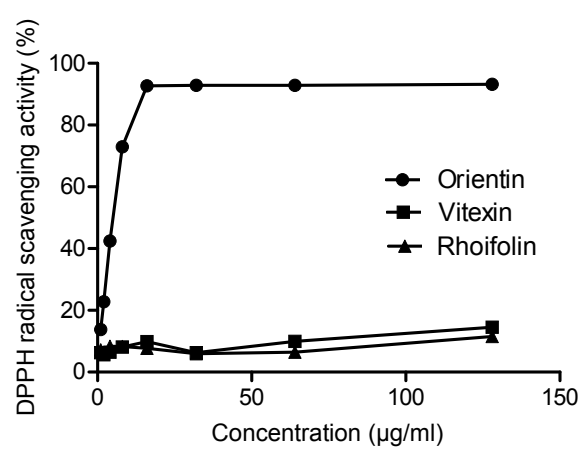

Fig. 3 Scavenging effects of flavonoids from leaves of J. curcas on $\mathrm{DPPH}^{\cdot}$ radicals.

Comparing to the other three flavonoids, the orientin had one more hydroxyl and contained pyrocatechol structure, so the orientin had a stronger ability to clearing free radicals ${ }^{23}$.

\section{LC-DAD-MS (ESI-) analysis of the collected fractions}

The ethanolic extract was further analysed by HPLCDAD in order to characterize the flavone compounds. UV spectra of this peak showed $\lambda_{\max }$ at 268 (267) and $338(350) \mathrm{nm}$, which are characteristic of apigenin (luteolin). LC-ESI/MS/MS indicates both methylated and sulphated forms of luteolin and apigenin are present as $c$-glycosides combined with up to one sugar residues, and apigenin is present as $O$-glycosides combined with up to two sugar residues. So it could choose standard substance according to these data. The data of the HPLC-DAD-ESI-MS ${ }^{\mathrm{n}}$ is summarized in Table 1.

The standard substances were given out at the same time with the extract by the same HPLC-DAD conditions (Fig. 4). Peak 2 and peak 3 are the isomeride from the data of the HPLC-DAD-ESI-MS ${ }^{\mathrm{n}}$ (Fig. 5). All data could help to identify the four compounds which were orientin (peak 1), vitexin (peak 2), isovitexin (peak 3), and rhoifolin (peak 4). 
Table 1 Characterization of the individual compounds in extracts using HPLC-DAD-ESI-MS ${ }^{\mathrm{n}}$.

\begin{tabular}{lcccll}
\hline Peak & $t_{\mathrm{R}}(\min )$ & $\lambda_{\max }(\mathrm{nm})^{\mathrm{a}}$ & {$[\mathrm{M}-\mathrm{H}]^{+} m / z$} & Formula & HPLC-ESI-MS; expt, $m / z(\%$ base peak) \\
\hline 1 & 6.52 & 267,350 & 449 & $\mathrm{C}_{21} \mathrm{H}_{21} \mathrm{O}_{11}$ & $\mathrm{MS}^{2}[449]: 431(100), 413(31), 383(49), 329(24)$ \\
2 & 7.83 & 268,338 & 433 & $\mathrm{C}_{21} \mathrm{H}_{21} \mathrm{O}_{10}$ & $\mathrm{MS}^{2}$ [433]: 415 (100), 397 (35), 367 (32), 313 (17) \\
3 & 8.91 & 268,338 & 433 & $\mathrm{C}_{21} \mathrm{H}_{21} \mathrm{O}_{10}$ & $\mathrm{MS}^{2}$ [433]: $415(100), 397(23), 367(73), 337(34)$ \\
4 & 12.01 & 268,338 & 579 & $\mathrm{C}_{27} \mathrm{H}_{31} \mathrm{O}_{14}$ & \\
\hline
\end{tabular}

${ }^{\text {a }}$ HPLC-DAD UV
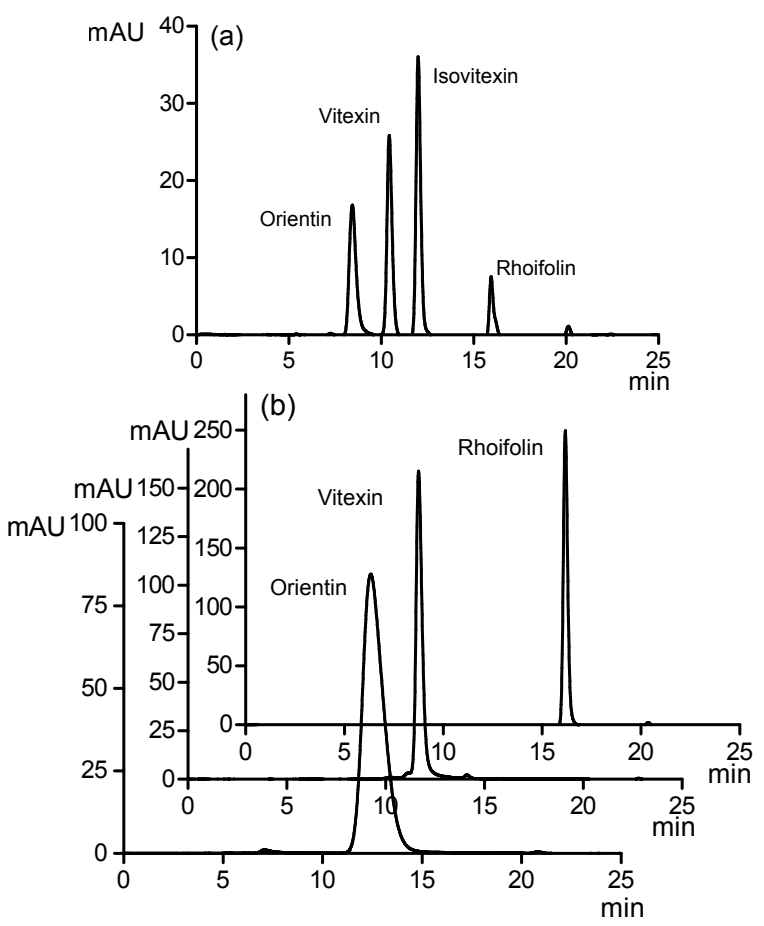

Fig. 4 HPLC chromatogram of flavonoids from (a) leaves of $J$. curcas and (b) standard substances, at a detection wavelength of $336 \mathrm{~nm}$.

The characterization of flavone compounds is important, as these compounds are associated with a range of different health properties. HPLC with diode array and mass spectrometric detection has proven to be very useful for the characterization of flavone compounds. In the present study, 4 compounds were characterized in J. curcas leaves, on basis of their UV spectral data and mass spectrometric analysis.

According to a previous report, J. curcas is not only a kind of very good oil plant, and the whole plant can be used in medicine for its subduing swelling eliminating stasis, antiviral, anticancer. The most promising phytochemicals are polyphenol and flavonoid compounds for their antioxidant properties. The vitexin, isovitexin, orientin, and rhoifolin are efficient antioxidants. For example, the antioxidant activity of rhoifolin was measured using the oxygen

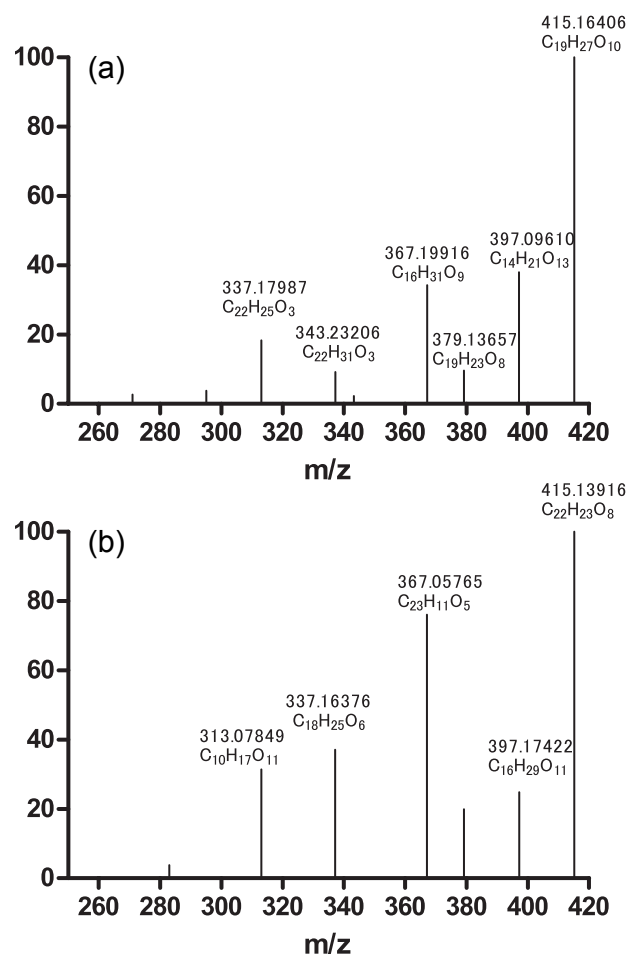

Fig. $5 \mathrm{MS}^{2}$ spectra of (a) isovitexin and (b) vitexin.

radical absorbance capacity which is an acknowledged method for antioxidant assessment ${ }^{23-26}$. The anticancer and antiviral effect of J. curcas may then be related to vitexin, isovitexin, orientin and rhoifolin.

In conclusion, in the absence of phytochemical and pharmacological information it is worth to elucidate the chemical and biological properties of leaves of J. curcas. The high content of antioxidants, compared with other species, depicts $J$. curcas as a medical plant that should be further investigated, and the evaluation of the antioxidant capacity using cellfree and cell-based assays highlights this study over others. The J. curcas was taken as energy plant, and the role of leaves in medicine will be beneficial to increase the added value. This study of leaves of $J$. curcas in oxidation and chemical composition laid an important foundation on the development and utilization in medicine. 
Acknowledgements: The research was supported by the Natural Key Technology R\&D Programme of the 12th FiveYear Plan of China (No: 2011BAD22B08).

\section{REFERENCES}

1. Richardson C, Koothanapath M, Sudthanom S (2005) The Role of Jatropha curcas in Support of the Thai Government's National Policy for Bio Diesel. Director General Department of Alternative Energy and Efficiency, Royal Government of Thailand, part 1, pp 25-33.

2. Prueksakorn K, Gheewala SH, Malakul P, Bonnet S (2010) Energy analysis of Jatropha plantation systems for biodiesel production in Thailand. Energ Sustain Dev 14, 1-5.

3. Yang CY, Fang Z, Li B, Long YF (2012) Review and prospects of Jatropha biodiesel industry in China. Renew Sustain Energ Rev 16, 2178-90.

4. Staubmann R, Ncube I, Gübitz GM, Steiner W, Read JS (1999) Esterase and lipase activity in Jatropha curcas L. seeds. J Biotechnol 75, 117-26.

5. Salimon J, Abdullah BM, Salih N (2012) D-optimal design optimization of Jatropha curcas L. seed oil hydrolysis via alkali-catalyzed reactions. Sains Malays 41, 731-8.

6. Pandey VC, Singh K, Singh JK, Kumar A, Singh B, Singh RP (2012) Jatropha curcas: A potential biofuel plant for sustainable environmental development. $R e$ new Sustain Energ Rev 16, 2870-83.

7. Kaushik N, Kumar K, Kumar S, Kaushik N, Roy S (2007) Genetic variability and divergence studies in seed traits and oil content of Jatropha (Jatropha curcas L.) accessions. Biomass Bioenerg 31, 497-502.

8. Becker K, Makkar HPS (2008) Jatropha curcas: A potential source for tomorrow's oil and biodiesel. Lipid Tech 20, 104-7.

9. Kovendan H, Murugan K, Panneerselvam C, Kumar PM, Amerasan D, Subramaniam J, Vincent S, Barnard DR (2012) Laboratory and field evaluation of medicinal plant extracts against filarial vector, Culex quinquefasciatus Say (Diptera: Culicidae). Parasitol Res 110, 2105-15.

10. Devappa RK, Rajesh SK, Kumar V, Makkar HPS, Becker K (2012) Activities of Jatropha curcas phorbol esters in various bioassays. Ecotoxicol Environ Saf 78, 57-62.

11. Oskoueian E, Abdullah N, Ahmad S, Saad WZ, Omar AR, Ho YW (2010) Bioactive compounds and biological activities of Jatropha curcas L. kernel meal extract. Int J Mol Sci 12, 5955-70.

12. Balasundram N, Sundram K, Samman S (2006) Phenolic compounds in plants and agri-industrial by-products: Antioxidant activity, occurrence, and potential uses. Food Chem 99, 191-203.

13. Caristi C, Bellocco E, Panzera V, Toscano G, Vadalà R, Leuzzi U (2003) Flavonoids detection by HPLC-DAD-
MS-MS in lemon juices from Sicilian cultivars. $J$ Agr Food Chem 51, 3528-34.

14. Papotti G, Bertelli D, Bortolotti L, Plessi M (2012) Chemical and functional characterization of Italian propolis obtained by different harvesting methods. J Agr Food Chem 60, 2852-62.

15. Yeşiloğlu Y, Şit L (2012) Antioxidant properties of various solvent extracts from purple basil. Spectrochim Acta A 95, 100-6.

16. Zou Y, Chang SKC, Gu Y, Qian SY (2011) Antioxidant activity and phenolic composition of lentil (Lens culinaris var. Morton) extract and its fractions. J Agr Food Chem 59, 2268-76.

17. Ferreres F, Gomes D, Valentão P, Gonçalves R, Pio R, Chagas EA, Seabra RM, Andrade PB (2009) Improved loquat (Eriobotrya japonica Lindl.) cultivars: Variation of phenolics and antioxidative potential. Food Chem 114, 1019-27.

18. Ayhan-Kılcıgil G, Çoban T, Tunçbilek M, Can-Eke B, Bozdağ-Dündar O, Ertan R, Iscan M (2004) Antioxidant properties of flavone- $6\left(4^{\prime}\right)$-carboxaldehyde oxime ether derivatives. Arch Pharm Res 27, 610-4.

19. Fernandes VC, Domingues VF, de Freitas V, DelerueMatos C, Mateus N (2012) Strawberries from integrated pest management and organic farming: Phenolic composition and antioxidant properties. Food Chem 134, 1926-31.

20. Hu QP, Xu JG (2011) Profiles of carotenoids, anthocyanins, phenolics, and antioxidant activity of selected color waxy corn grains during maturation. J Agr Food Chem 59, 2026-33.

21. Debnath T, Park PJ, Deb Nath NC, Samad NB, Park HW, Lim BO (2011) Antioxidant activity of Gardenia jasminoides Ellis fruit extracts. Food Chem 128, 697-703.

22. Dorman HJD, Peltoketo A, Hiltunen R, Tikkanen MJ (2003) Characterisation of the antioxidant properties of de-odourised aqueous extracts from selected Lamiaceae herbs. Food Chem 83, 255-62.

23. de Souza Gil E, Enache AT, de Oliveira-Brett AM (2012) Anodic behavior of flavonoids orientin, eriodictyol and robinin at a glassy carbon electrode. Electroanalysis 24, 1576-83.

24. Joubert E, de Beer D (2012) Phenolic content and antioxidant activity of rooibos food ingredient extracts. J Food Compos Anal 27, 45-51.

25. Adwan G, Abu-Shanab B, Adwan K (2010) Antibacterial activities of some plant extracts alone and in combination with different antimicrobials against multidrugresistant Pseudomonas aeruginosa strains. Asian Pac J Trop Med 3, 266-9.

26. Li H, Cao D, Yi J, Cao J, Jiang W (2012) Identification of the flavonoids in mungbean (Phaseolus radiatus $\mathrm{L}$.) soup and their antioxidant activities. Food Chem 135, 2942-6. 